\title{
Research on the Development Policies of Modern Logistics Industrial Cluster
}

\author{
Take Wuhu for Example
}

\author{
Banglei Wu \\ Department of Economic and Trade Management \\ Anhui Technical College of Mechanical and Electrical Engineering \\ Wuhu, Anhui, China 241000
}

\author{
Zhiguo Yu \\ Department of Economic and Trade Management \\ Anhui Technical College of Mechanical and Electrical \\ Engineering \\ Wuhu, Anhui, China 241000
}

\author{
Yun $\mathrm{He}$ \\ Department of Economic and Trade Management \\ Anhui Technical College of Mechanical and Electrical \\ Engineering \\ Wuhu, Anhui, China 241000
}

\begin{abstract}
Development level of logistics industry in Wuhu is low, and there is still a huge gap between the modern logistics industry cluster. The development of industrial clusters should take the government as the leading, and the development of Wuhu manufacturing industrial cluster is in accordance with this law. The construction and development of logistics industrial cluster has to be based on the development of other industries. The level of development of other industries determines the development of the logistics industrial cluster. In the construction of modern logistics industry cluster in Wuhu, the government should pay attention to the following three aspects: first, it should strengthen the relationship between the development of manufacturing industrial clusters and the construction of logistics industrial cluster. Second, the construction of the logistics industrial cluster should break through the restriction of localization, and carry on the cross regional development. Third, it should build the logistics information platform for small and medium sized logistics enterprises.
\end{abstract}

Keywords-modern logistics industrial cluster; organizational succession; development policies

\section{INTRODUCTION}

In the aspects of countermeasure research on modern logistics industrial cluster development, the research tool adopted by the researchers mainly use common industry cluster research tools, these analysis tools suitable for manufacturing industry cluster are often directly used to the research on logistics industry cluster. The most traditional research tools are enterprise's strategy analysis tools such as diamond model and improved GEM model, basing on these research tools, some scholars have proposed path optimizing strategy in the three levels of basis, enterprises and market for the construction of logistics industry cluster [1]. Some

Fund Project: "Logistics Management Specialty" provincial quality project of colleges and universities in Anhui in 2014 (2014tszy073). Wuhu soft science research project (2014rkx10).

CLC NO.:F062.9 other scholars carry out research on regional logistics industry cluster development policy by using the symbiosis theory, specialization theory of new classical economics and the infra-marginal analysis method as theory tool [2]. More popular tools are mostly the theories related to systems theory, self-organization theory and synergetics, some scholars have constructed a coordination mechanism between different logistics industry clusters basing on this [3].

On the method of development countermeasure research, most scholars carry out analysis to logistics industrial cluster by taking it as an independent subject, and the proposed suggestions and strategies mostly confined to the logistics industry itself. For example, some scholars have suggested that the government shall build competitive and orderly symbiosis mechanism by taking the advantage of logistics industry associations to create a good symbiotic environment and construct a fair competition of platform and environment for all types of logistics industrial symbiosis unit [4]. There are some other scholars carry out analysis by combining the logistics industrial cluster and the logistics park, even some scholars have proposed that clustering operation is the inevitable path to enhance the competitiveness of modern logistics park [5]. For the research with more broad perspectives, the research is carried out to the regional logistics integration from the perspective of regional integration, for example, some scholars discussed the

The regional industrial cluster of the industry, regional logistics integration innovation and development and the interactive system construction related to the industry from the perspective of modern regional logistics area [6].

In general, the most researchers of development of modern logistics industrial cluster failed to associate other industries, especially the manufacturing industry cluster with the development of modern logistics industrial cluster. 
Although some people have recognized that the industrial clusters in other industries are closely related to modern logistics, they believed that the development of other industrial clusters depends on the development of modern logistics, and construction of other industrial cluster shall base on modern commodity-interflow platform [7]. Our view is on the contrary, the modern logistics industrial cluster shall base on the development of other industrial cluster, especially the development of manufacturing industry cluster, and we take Wuhu as a case for analysis to provide broader perspective and ideas for the countermeasures of modern logistics industrial cluster.

\section{PRESENT SituAtion OF DEVELOPMENT OF LOGISTICS INDUSTRIAL CLUSTER IN WUHU}

Wuhu is the material distribution center of the area along the Yangtze River in southeastern Anhui, and it is an important regional logistics center city in the province, but also the inevitable place for transformation from eastern coast to the mainland industry, it possesses an outstanding strategic position in regional economic development. The telecommunications communication capabilities, technical level and service level in Wuhu all rank the forefront of the industry in the province. Wuhu is an important hub in railway tunnel of Eastern China. The highway transport network in Wuhu is relative sound, which plays a pivotal role in the transportation of central region. And the waterway in Wuhu has unparalleled advantages, there are more than 200 wharfs of various types and the Wuhu-Shanghai canal is under construction. Therefore, the development of modern logistics industrial cluster in Wuhu has a good foundation.

However, the current situation of logistics industry in Wuhu is not optimistic. According to the investigation and research of local investigation team of National Bureau [8], the logistics industry in Wuhu mainly is traditional freight warehousing, the third party logistics companies in the true sense is less than $10 \%$. The governance system of the government on logistics industry is still the multiple leadership ways of highly fragmented and segmentary system and department separation leadership on the aspects of waterways, roads, rail ways, which has form bottleneck to the system.

Because the different modes of transportation is governed by different departments, and the purposes and specifications of each competent departments are different which makes the coordination of combined transport among the logistics enterprises is difficult and resulting in dispersion, excessive competition and low service quality in the operation of logistics enterprise. In addition, the scale of logistics enterprises is relative small while with the characteristics of poor strength and management, single and original service mode, low service innovation ability. Most of them still stay in the single service items of freight forwarding, warehousing, inventory management, handling and truck transportation, the modern logistics enterprises which can provide comprehensive, whole process and integrated service is rare.
Porter believes that cluster is a kind of phenomenon that the company or institutions with relations in a specific industry gathered in a specific geographic location. The cluster including a series of upper, middle and downstream industries and other enterprises or institutions which is very important to the competition, they includes the suppliers of special materials such as spare parts, equipment and services and the providers of special infrastructure construction. Clusters usually extends down to the path or the customer of the downstream, also extends to the manufacturers of complementary products and companies on the aspects related to the skills, science and technology or common raw materials in the industry. Finally, cluster also includes government and institutions providing professional training, education, information and research and technical support, such as universities, standard-setting bodies, vocational training centers and business organizations [9]. According to Porter, logistics industrial cluster shall be an organic integrity composed by many enterprises with close coordination relationship in logistics industry aspects, such as government agencies, universities and research institutes together in a specific geographical location. So, there is still a huge gap in the completion of modern logistics industrial cluster in the aspects of professional, social or information.

\section{ORGANIZATIONAL SUCCESSION AND DEVELOPMENT OF MODERN LOGISTICS INDUSTRIAL CLUSTER}

Industrial cluster is a kind of nonlinear system, and there is no exception for logistics industrial cluster [10]. Logistics industrial cluster has a locking phenomenon. When the system reaches a stationary state, as it is stable within a certain range, and locking phenomenon will occur if the system cannot reach the critical threshold. For example, in logistics industrial cluster, the operation philosophy and vision among different enterprise is different, in the assumption of rational man supposition, the motive of market benefit maximization drives the independence among the individual enterprises and forms loose unorganized concentration phenomenon. The conflict in the cluster is unceasing, while the networking and the locking of collective action among enterprises cluster will hinder the occurrence of innovation effect of cluster aggregation, so that the cluster cannot form an ordered organic systems with competitive advantage. And the evolution of industrial cluster has the characteristics of irreversible, bifurcation and path dependence. The evolution of logistics industrial cluster generally has several steady-state solutions, and the evolution process of these steady-state solutions is a bifurcation. When exogenous parameter changes and exceeds a certain critical value, the evolution direction of the number of economy steady-states or the changes in stability will be selected randomly by the system. Even the final results of logistics industrial cluster evolution tends to steady-state, in the freedom system without control variables, whether can achieve optimal or suboptimal steady-state is random and unpredictable. Once the industrial cluster randomly evolved to a certain state, this state determines the future state which can be achieved in the future, that is the path dependence of the industrial cluster evolution of the past determining the future. In addition, the evolution of 
logistics industrial cluster has the characteristics of mutability and chaos.

Therefore, the development of logistics industrial cluster needs the government to develop a scientific planning according to the economic trends and regional characteristics, to promote the healthy and stable development of industrial cluster in planning guidelines in order to prevent from falling into the locking trap. The cultivation and formation process of logistics industrial cluster requires government guidance, care and support. The government shall establish a good talent exchange mechanism and information sharing mechanism to promote the rational flow of production factors within the cluster and strengthen the dependencies between enterprises. It is necessary for the government to maintain the stability of the factors in logistics industrial cluster to reach the goal of cultivating the clusters basing on a certain direction and expectation. The role of government in the formation and evolution of industrial cluster is endogenous, only the government's various acts and policies become endogenous to the formation and evolution of industrial cluster, can they play an active and leading role.

The industrial cluster construction in Wuhu is generally developed under the guidance of the government. The construction and development in Wuhu has three notable features: firstly, the industrial cluster is combined with construction of industrial park. The local governments take the industrial park as a platform to cultivate pillar industries and take building industrial cluster as the goal. For example, the early cars, electronics, new materials and wire and cable industries, such as the automobile and parts industrial cluster represented by Chery and electrical and electronic industrial cluster represented by Mieda, and the new material industrial cluster represented by Conch, Knauf, Xinxing Pipes has become a pillar industry. The recently promoted industrial robots industrial cluster, electronic information industrial cluster, new energy industrial cluster and general aviation industrial cluster are inseparable with industrial park planning and construction. Secondly, the high-tech technicalization of the industry mainly for the enhancement of the independent innovation capability. Such as the recent robots, electronic information industrial cluster is the pilot of the national strategic burgeoning industry cluster development. The automotive field has become the national new energy auto pilot innovative industrial cluster. Thirdly, many industrial clusters has achieved the great-leap-forward development from scratch and to gradually improved under the effect of local government.

The government's leading function to the logistics industrial cluster is start from the organization succession phenomenon. This concept is summarized by Gary Roffey when he was researching spinning industrial cluster. Organization succession refers to that the most industrial cluster in relatively underdeveloped area undertake the low value-added manufacturing links in the global value chains transferred from the industries of other developed countries, where after, the degree of specialization increases as the development of cluster and begin to expand to the high value-added links in the value chain and form a complete supply chain system, and finally complete the upgrade and transition of industrial cluster [11].

Thus it can be seen that, the construction of logistics industrial cluster substantially is other industrial cluster such as automobile and its parts and electrical equipments, new materials and industrial robots successes along with the origination, and the supply chain is also synchronously perfected in the general perfecting process of value chain [12]. This is because other industrial cluster needs to take supply chain as a platform for coordination, and they need to gradually outsource the non-core businesses of the logistics in order to improve the quality of the core business thus to make the logistics operation of the enterprise in the other industrial clusters and form an integrated logistics process.

The supply chain of other industrial cluster in the clustered enterprise of organization succession process has logistics contact on two dimensions of vertical and horizontal dimensions with the related cluster enterprise [13]. Therefore, organization succession of cluster development can be carried out on both longitudinal dimension and horizontal dimension. What we call longitudinal succession refers to industrial cluster forms a complete function network chain to achieve integration in the local market of the supply chain. The specialization of labor division among enterprises can play the advantages of the cluster division of labor. And expand from manufacturing links to production and procurement of key parts, research and design and brand marketing extension, thus to increase the added value and complete the value chain upgrade. What we call horizontal succession refers to number increasing and strength enhancement of enterprises in the same supply chain links within the industrial cluster. Strengthen and expand the one or some links of the value chain, enhance core competitiveness, so as to enhance the advantages of industrial cluster. The integrity of logistics activities can be created through vertical and horizontal organization succession [14], and the logistics industrial cluster formed in this way may be involved in various aspects of logistics integration.

Therefore, the construction and development of logistics industrial cluster must take the development of other industrial cluster as a foundation. And the development level of other industrial cluster determines the boundaries of logistics industrial cluster development. The development levels of other industrial cluster are higher, and the cooperation and contact among the cluster enterprises are more closely, the development of logistics industrial cluster will be relative high. Conversely, if the links between cluster enterprises is loose, the logistics industrial cluster is difficult to form in the true sense. Only when the construction of other industrial cluster reaches to a certain extent, logistics industrial cluster can be formed.

\section{CONCLUSION AND SUGGESTIONS}

In essence, logistics industrial cluster the results of outsourcing of enterprise logistics activities and integration in other industrial cluster. Only strengthen the leading functions of the government and positively promote the development 
level of various industrial clusters, finally it can be presented in the construction process of logistics activities integration of logistics industrial cluster.

In the construction of modern logistics industrial cluster of Wuhu, the government shall play a role in the following three functions:

Firstly, strengthen the connection between the development of manufacturing industrial clusters and construction of logistics industrial cluster. Basing on the completed or under construction manufacturing industrial clusters of automobile and its parts, electricity \& electronics, new materials, wire and cable manufacturing industry, industrial robots, electronic information, new energy and general aviation and so on, it takes logistics hub facilities as a platform and actively create a modern logistics park for different industry and services, to enhance the level of logistics services, encourage the enterprise in manufacturing industrial clusters outsource the self-run logistics to the logistics companies with high credit quality and good credit and focus the limited resources of the enterprises to their own core business, and promote the specialization of labor division and socialization of production, thus cannot only strengthen the construction of modern logistics industrial cluster, it can promote the development of manufacturing industrial clusters and enhance the market competitiveness of cluster and enterprise within the cluster in turn.

Secondly, the construction of logistics industrial cluster shall break localized restrictions and proceed cross-regional development. Most manufacturing industrial clusters shall not be limited to one city in one place, from the view of local manufacturing industrial clusters in Wuhu, mostly industries of automobiles and its parts, new materials, robotics and general aviation and so on are transregional and even transnational industry. The construction of modern logistics industrial cluster in Wuhu shall break regional restrictions and consider the transregional and transnational logistics operation activities from a broader perspective. Thus, in the long run, the construction on logistics industrial cluster in Wuhu shall adopt the way of great-leap-forward development to cultivate or introduce transregional thirdparty logistics companies with strong comprehensiveness and high service quality to break through the bottleneck of the current low levels.

Thirdly, take great effort to construct a logistics information platform for small and medium sized logistics enterprise services. In order to adapt to the current situation of small scale of most logistics enterprises, we shall transfer the disadvantages into advantages through information integration. Neither cultivating nor introducing high level of logistics enterprises cannot change the current situation that the logistics enterprises are small and medium sized enterprises in the short term. Therefore, in the short term, we shall take great effort to construct a logistics information platform system for providing small and medium sized logistics enterprise, and coordinate the cooperation and communication between the small and medium sized logistics enterprises and other enterprises through information exchange and sharing among the logistics enterprises and manufacturing enterprises, to make the logistics industrial cluster itself can collaboratively develop with other industrial clusters.

\section{REFERENCES}

[1] Huang Taozhen. Competitive Advantages and Route Optimization of Modern Logistics Industrial Cluster based on GEM and Diamond Model - in Wuxi City [J]. Nanning: Academic Forum, 2015(7):71-75.

[2] Yang Chunhe. Research on the Formation of Modern Logistics Industrial Cluster and Evolution Models [D]. Beijing: Beijing Jiaotong University, 2008.

[3] Guo Qiang. Research on Coordination Mechanism of Logistics Industrial Clusters [D]. Wuhan: Wuhan University, 2012.

[4] Wu Di. Analysis on Development Mechanism and Support Policies of Logistics Industrial Cluster under Symbiosis Theory.

[5] Zhang liangwei, Li Xin, Li Yuting. Discussion on Cluster Management Mode of Modern Logistics Parks under the Perspective of Logistics Industrial Cluster.

[6] Ma Lin. Research Summary on Modern Logistics Industrial Cluster based on Regional Integration [J] .Changchun: Industrial Technology \& Economy, 2007 (12): 144-146.

[7] Gao Kang. Construction of Modern Logistics Platform of Industrial Cluster in Liaoning Province [J]. Shenyang: Journal of Shenyang University, 2011 (3) :31-34.

[8] Wuhu Enterprise Investigation Team, State Statistics Bureau. Analysis on Current Situation of Modern Logistics in Wuhu [N/OL]. Public Service Network of Survey Office of the National Bureau of Statistics in Anhui. http://www.ahdc.gov.cn/dt2111111144.asp?DocID=2111111974.

[9] Porter M.E. Clusters and the New Economies of Competition [J].Harvard Business Review.1998 (1):77-90.

[10] She Zhiguo, Da Binghong. See the Role of Government in the Construction of Industrial Cluster from the Nonlinearity of Industrial Cluster [J]. Journal of Anhui University of Technology (Social Science Edition)

[11] Gereffi Gary. International Trade and Industrial Upgrading in the Apparel Commodity Chain $[\mathrm{J}]$. Journal of International Economics, 1999, 43 (2): 3211-3223.

[12] Li Jizi, Liu Chunling, Chang Chunling, Li Boxun. Coupling Analysis on cluster of supply chain organization succession and development of logistics park - A Case Study of Suzhou IT industrial cluster [J] China Soft Science, 2006 (1): 108-116.

[13] Cao Lili, Yang Tingting. Countermeasures Study on Industrial Cluster Upgrade Based on Supply Chain Organization Succession [J] Hubei Social Sciences, 2014 (9): 89-91.

[14] Wang Jing. Supply Chain Organization based on Industrial Cluster and Development Model of logistics Park [J]. Journal of Northwest Sci Tech University of Agriculture and Forestry (Social Science Edition), 2008 (3): 54-57.

[15] Jiang Mingzhu. Empirical Research on Regional Logistics Capability and Innovation of the Development Relations [J]. Business Economics Research 2015 (26). 